\section{Política y trabajo en salud: ¿la pandemia de COVID-19 como acontecimiento?}

\author{
Health policy and healthcare work: the COVID-19 \\ pandemic as an event?
}

Política e trabalho em saúde: a pandemia de COVID-19 como evento?
Leonardo Federico 1

doi: 10.1590/0102-311X00240120

\section{Resumen}

La pandemia de COVID-19 ha irrumpido en el mundo de un modo sorpresivo, trastocando el estado previo de la situación de los países afectados, así como la situación de sus respectivos Estados. "Lo real" se ha resignificado a partir de sus graves derivaciones. La Argentina no constituye una excepción $y$, por lo tanto, sus ciudadanos y el propio Estado fueron interpelados y convocados a asumir un posicionamiento singular basado en valores, $y$ realizar acciones tendientes a afrontar sus consecuencias, tanto inmediatas como mediatas. Por ello, en el presente Ensayo se piensa la pandemia en términos de "acontecimiento", siguiendo la propuesta conceptual del filósofo francés Alain Badiou, y se analizan sus implicancias sobre la subjetivación individual $y$ colectiva, los valores que orientan las prácticas, el rol de los medios de comunicación, y el posicionamiento asumido por el Estado argentino; así como también sus repercusiones más específicas en la política y el trabajo en salud, apelando a otros referentes teóricos del campo. Se destaca que el modo en que se implementa "la politica" en el presente contexto, de no mediar una profunda reflexión y reorientación de las prácticas priorizando lo micropolítico, redundará en una mayor desvinculación y alienación de los sujetos individuales y colectivos. El acontecimiento entonces, más que la pandemia, que ya es un hecho, deberá constituirlo la articulación intersubjetiva de un abordaje saludable de sus consecuencias, tendiente a la integralidad y la igualdad en defensa de la vida.

Pandemias; Política de Salud; Trabajo

\author{
Correspondencia \\ L. Federico \\ Lomas de Zamora / Buenos Aires - 1828, Argentina. \\ leofederico68@gmail.com \\ 1 Universidad Nacional de Mar del Plata, Mar del Plata, \\ Argentina.
}




\section{Introducción}

En este Ensayo propongo pensar la pandemia de COVID-19 en términos de "acontecimiento", con el objeto de contribuir a la reflexión teórica sobre la situación actual en el campo de la salud en Argentina. Las preguntas que orientan el texto son: ¿por qué la pandemia constituye un acontecimiento? y, ¿cuáles son sus posibles implicancias sobre la política y el trabajo en salud?

Para dar esta discusión me apoyaré inicialmente en la propuesta conceptual del filósofo francés Alain Badiou, con énfasis en su concepción del "acontecimiento", para, a partir de ese marco, profundizar la discusión sobre la política y el trabajo en salud en el presente contexto, apelando a otros referentes teóricos del campo.

\section{Acerca del "acontecimiento" y sus derivaciones}

La primera cuestión que quiero tomar de Badiou es su convocatoria -basada en la alegoría platónica- a que salgamos de "la caverna" (simbolizada aquí en -pero sin reducirla a- la pantalla televisiva alienante) 1. Salir de la caverna para saber que el mundo está bajo la ley de un "semblante" -lo podríamos traducir como una máscara-, y que hay que escapar del lugar que ese semblante simulucrativo (simulacro lucrativo) organiza bajo la forma de un discurso único, dominante, para acceder a "lo real". Todo real se revela entonces en la ruina de un semblante, es decir, a partir de un desenmascaramiento 2.

Sabemos que los medios masivos de comunicación en la actualidad nos proponen en forma constante, y a la vez instantánea, un espectáculo sin historia, sin memoria, que reconstruye en forma obstinada el semblante apariencial de la realidad. Esto nos obliga, en tanto trabajadores de las áreas sociales, a ejercer una especie de vigilancia permanente, dado que la perpetuación de la dominación de las clases dominantes consiste precisamente en volver invisibles sus propios intereses y privilegios, a partir de la naturalización del semblante 3,4. De aquí la importancia de recrear el pensamiento político como una decisión ligada a la ruptura, que comience con un desenmascaramiento de tales intereses, tan amplio como sea posible 5,6,7.

La pandemia actual provocó cierto desvelamiento, y se visibilizaron cuestiones que fueron señaladas por diferentes intelectuales 8,9, como por ejemplo: que ningún Estado-Nación pudo predecir ni prever este escenario; que la economía era menos consistente de lo que se suponía, inclusive la de las superpotencias; el consumismo innecesario y la contaminación exagerada; que ningún Sistema de Salud estaba capacitado para hacer frente a una situación de estas características; la insuficiencia de los saberes expertos y la gestión para articular una respuesta eficaz, por lo cual es convocada la política; el hecho de que los países -históricamente- "invasores" (coloniales), no supieran qué hacer al verse invadidos; en síntesis, que la "normalidad" previa -que tanto se añora- dejaba mucho que desear como ideal de vida en sociedad.

Partiré entonces del supuesto de que estamos, efectivamente, ante la irrupción de un acontecimiento. Cuando un acontecimiento acaece moviliza los elementos de su sitio, y en ello reside su potencial transformador, transfigurador, dado que se halla -aparentemente- desligado de las reglas y recursos que regían -y a partir de los cuales se explicaba- la situación previa. El acontecimiento es entonces, en función de sus consecuencias sobre la situación. Este carácter de "suplemento azaroso", de añadido desconcertante, sumado a su capacidad de engendrar una temporalidad propia, revelan su impredecibilidad constitutiva -aun cuando luego puedan explicarse las causas de su irrupción en forma retrospectiva- 10,11. Es fundamental aclarar que, a pesar de que estas reflexiones estén motivadas por una pandemia que afectó a la mayoría de los países del planeta, la definición de los sitios del acontecimiento siempre es "local", ya que implica un sitio singularizable en una situación histórica concreta; por lo cual, aunque por momentos se generalice, la discusión está enfocada en la experiencia de Argentina.

Ahora bien, el acontecimiento no solo subvierte el estado de la situación, sino que también subvierte la situación del Estado (de los Estados-Nación). El Estado expresa, en circunstancias "normales", un poder-potencia más bien indeterminado -y por lo mismo eficaz para evitar novedosas trayectorias sociales-, pero ante la irrupción del acontecimiento-pandemia, como ruptura de la situación, se ve conminado a fijar su posición y así objetivar de algún modo su poder-potencia. Esta es una primera 
condición que el acontecimiento impone al Estado, constituyendo así una política de ruptura. Esta toma de posición (política) puede ser comisiva -reactiva o proactiva- o por omisión; pero en cualquier caso implicará una ruptura en tanto se estará decidiendo y ejerciendo algo muy diferente a lo pautado de no haber existido el acontecimiento. De este modo, la política hace visible lo invisible propio del estado de la situación, al requerir que se manifieste en forma explícita la potencia del Estado 10,12,13.

Una segunda condición que el acontecimiento impone a la sociedad en su conjunto es la convocatoria a que las personas y los diferentes grupos de interés asuman una posición de "fidelidad" a la ruptura planteada por el acontecimiento; que la comunidad decida desarrollar consecuencias a partir de las consecuencias derivadas del acontecimiento, es decir, que decida pensar la ruptura y desarrollarla como política ${ }^{14}$. En suma, dada esta estructura implicativa del acontecimiento, se convoca una actitud de apuesta de carácter "militante", una configuración subjetiva proactiva -individual y colectiva- que se desarrolle y consolide como síntesis entre pensamiento y acción. Una afición de la voluntad colectiva capaz de viabilizar el tratamiento de los posibles... a partir de la unidad que el pensamiento forma con su advenimiento 11 . Colectivo no es aquí un concepto numérico, sino más bien una referencia a "lo múltiple" como parte de la situación. Siguiendo al autor, decimos que "el acontecimiento es ontológicamente colectivo en la medida en que vehiculiza un requerimiento virtual de todos" 10 (p. 109); nos interpela y provoca a todos, y a cada uno, en tanto posibilidad abierta a que el sujeto encuentre su propia implicación subjetiva 15 .

La tercera condición es que haya valores orientadores que caractericen y definan la toma de posición. Que a partir de la ruptura de la situación se enuncien principios sensibles fundamentales de la política. Fundamentales también en el sentido de que la fundamenten. Si se revisan, por ejemplo, las sucesivas conferencias de prensa del Presidente Alberto Fernández durante la pandemia, se explicitan estos principios constitutivos de una "Idea" que los integra: "la defensa de la vida" -sobre la priorización de la economía-; "la solidaridad"; "la igualdad". La igualdad deslindada de una connotación económica objetivista, e investida de su punzante filo subjetivo en lucha contra las desigualdades (provocadas y sostenidas por la dominación capitalista, colonialista y patriarcal) 16. La igualdad no como un programa, sino más bien como una definición fundada en la autoridad de "lo Mismo" 14; la capacidad para funcionar plenamente como seres humanos ${ }^{17}$. Para ser más claro, propongo que adoptemos al respecto el axioma de Boaventura de Sousa Santos 18 (p. 154): “...tenemos el derecho a ser iguales cada vez que la diferencia nos inferioriza (nos vulnera, nos enferma, nos mata); [y] tenemos derecho a ser diferentes cuando la igualdad nos descaracteriza". Es importante aclarar que, para Badiou, estos son los principios de la presentación colectiva y no meramente los principios de su representación; vale decir, no son los principios del presidente y sus ministros que incluyen a la ciudadanía en tanto la representan, sino más bien los principios en que el pueblo, como múltiple activo, se presenta ante el acontecimiento perteneciendo en la situación 11.

Esta implicación, en algún punto ineludible, de individuos y grupos con el acontecimiento acaecido, derivará en su re-subjetivación. Hay así una relación dialéctica entre acontecimiento y sujetos: el acontecimiento se hace visible, porque es reconocido, nominado y asumido por los sujetos; pero el acontecimiento a su vez solo puede ser visible (significativo) para quienes hayan sido interpelados, inducidos a tomar decisiones e intervenir tras su ocurrencia. Entonces, la idea de sujeto no se aplica aquí a un atributo constitutivo de lo que somos, sino más bien a una experiencia que los actores son capaces de vivir y desarrollar en determinadas condiciones y circunstancias 19.

En tal sentido, un acontecimiento abre un espacio de subjetivación que da lugar a tres figuras posibles de posicionamiento subjetivo (que solo serán puras en términos teóricos):

- Fiel: es aquel que deviene sujeto de transformación, aceptando las consecuencias del acontecimiento, organizando el tiempo y el cuerpo en el hacer, reagrupándose; ejerciendo un discernimiento activo sobre lo que llegó para conmocionar las leyes del (y de su) mundo. Así, los resultados de los procedimientos encarnados por los sujetos fieles operan sobre el terreno del estado de la situación, modificándolo. Vale aclarar que tal fidelidad no es producto de un proceso sapiente ligado exclusivamente al conocimiento y la razón, sino más bien un procedimiento de carácter "militante". Ahora bien, para una misma situación y para un mismo acontecimiento, existirán criterios variables que definen modos diferenciales de ejercer la fidelidad, de pertenecer en la situación. Como en el amor, desde este posicionamiento se confía en la diferencia, en lugar de sospecharla 20. Los valores y principios a los que aludimos anteriormente (defensa de la vida, solidaridad, igualdad), influyen sobre 
las posibilidades de consolidar dicha pertenencia como operadores de conexiones intersubjetivas de fidelidad; pero aclaremos que lo difícil de la fidelidad es su ejercicio, más que sus criterios de inclusión y validación. Badiou 11 (p. 260) señala además que, “...siempre hay algo de institucional en una fidelidad, si entendemos por institución, de manera muy general, lo que está en el espacio de la representación, del Estado...”. No obstante, tal fidelidad no será exclusivamente estatal en tanto ella organiza, en la situación, otra legitimidad de las inclusiones y pertenencias diferentes al "rebaño de los fieles" de las ligazones institucionalizadas 11. En conclusión, a partir de este posicionamiento subjetivo, el "nosotros de la Idea" se antepone a un "nosotros de la Identidad" (en especial, cuando este adquiere un carácter exclusivo y excluyente) 19 .

- Reactivo: en este posicionamiento prima la indiferencia negadora, el hacer como si nada hubiera pasado...; es decir, que tiende a anular la novedad en la potencia tranquilizadora de la conservación de las formas económicas, políticas, institucionales, culturales, anteriores. Es el presente de la disimulación del presente, manteniendo el semblante de la continuidad, negando la efectividad del acontecimiento. Es el sujeto que en el amor se rehúsa a asumir el riesgo que este implica, si no cuenta con sólidas garantías contractuales; lo que en términos sociales equivaldría a anteponer la lógica "interesada" gerencial, administrativa, a la política. En resumen, el amor sin amor y la política sin política. - Oscuro: encarna la hostilidad del "celoso" obsesionado por la posible infidelidad del "otro", que amenaza la continuidad de "lo Uno supuesto" que ambos, para él, constituyen. En lo que nos ocupa, digamos que considera a lo nuevo como una irrupción "extranjera", nociva, a ser erradicada, destruida. Constituye un posicionamiento basado en un odio oscurantista y beligerante, y así, el cuerpo que invoca este posicionamiento no es acontecimiental, sino sustancial, equiparando "lo nocivo" de hoy a otros enemigos "esenciales" anteriores, sean de carácter racial, político o religioso. Su convocatoria entonces es para perseguir y destruir toda manifestación de la contingencia donde se manifieste un riesgo mortal ligado a la infidelidad de ese otro. Actitud narcisista y a la vez fascista que, como se dijo, prefiere la destrucción integral al desfallecimiento de lo "Uno supuesto" (el "nosotros de la Identidad” exclusiva y excluyente) ante la irrupción de lo aleatorio acontecimiental en la estructura del mundo 13,21. Basta pensar en algunos líderes mundiales, y en sus respectivos posicionamientos durante estos meses de pandemia, para eximirme de dar mayores referencias empíricas explicativas.

Como ha quedado sugerido tras esta caracterización de las tres figuras posibles de posicionamiento subjetivo, siempre que los sujetos consigan liberarse de las exigencias autocentradas o conservadoras y logren reivindicar imperativos transindividuales, tales reivindicaciones podrán asumir la forma de una voluntad colectiva en pos de la igualdad, movilizando la aspiración emancipadora de "un nosotros de la Idea" al cual se pertenece para desarrollarlo 19. Algo bien diferente a "estar enamorados de la cuarentena", como señalaron en forma tan insistente como reduccionista, los comunicadores sociales opositores.

“...Gracias a la fuerza de un acontecimiento, muchas personas descubren que lo real del mundo puede situarse en algo que es simplemente imposible, desde el punto de vista dominante de ese mismo mundo" 22 (p. 76).

De este modo, la apuesta de fidelidad al acontecimiento podría hacer de nosotros sujetos embarcados en un proceso colectivo de transformación que determine una visión común de nuestras voluntades asociadas, capaz de abrir nuevas posibilidades de vida, pensamiento y acción; nuevas posibilidades de ser, hacer y pertenecer develando y potenciando lo que hay de "común" en lo real 2,19.

\section{La política y el trabajo en salud a partir del acontecimiento}

No es novedad para nadie que las fuerzas reaccionarias seguirán concentradas en impedir toda política que pretenda modificar el statu quo, oponiéndose al acontecimiento, a la emergencia de nuevos actores sociales y a los valores que orienten sus prácticas (la defensa de la vida, la solidaridad, la igualdad), y a todo aquello que ponga en cuestión la propiedad privada y la libertad del mercado; incluyendo, si fuera necesario, a la propia democracia republicana que a menudo se presenta como el "semblante" más eficaz para garantizar su supremacía 2.

Si bien el nivel de acatamiento general a las medidas adoptadas por el gobierno fue alto, muchos grupos de las clases más "acomodadas" de nuestro país, solo cumplieron en forma estricta con la "cuarentena" durante el lapso de semanas en que se sintieron particularmente amenazados. Cuando 
la pandemia comenzó a azotar con mayor rigor a los barrios populares, muchos de ellos se dedicaron a transgredir y demonizar la cuarentena sin miramientos. Este proceder es más irresponsable aún, si consideramos que el aislamiento social, preventivo y obligatorio es de por sí discriminatorio, porque, aunque parezca igualitario, hay determinados grupos sociales que tienen más facilidad para cumplirlo que otros, y además en general, quienes más dificultades estructurales tienen para acatarlo, suelen ser "los cuidadores" de quienes tienen mayores facilidades; lo que implica una enorme desigualdad. No es simple lidiar con esto cuando desde la propia Organización Mundial de la Salud (OMS) se prescriben medidas enfocadas en una idealizada "clase media" que es absolutamente minoritaria en los países de América Latina 8 .

La política entonces no debiera asumirse como "el arte de lo posible", sino más bien como la creación de nuevas condiciones de posibilidad tendientes a la igualdad; inclusive de posibilidades que no conocemos. Por eso, he planteado al comienzo de este ensayo que, ante la irrupción de un acontecimiento de semejante envergadura, capaz de desnudar las severas limitaciones de los saberes expertos y la gestión de las instituciones tradicionales para hacer frente a sus inusuales consecuencias, es convocada la política. Llegados a este punto, quisiera apelar a una distinción conceptual fundamental entra "la política" y "lo político". Chantal Mouffe plantea que mientras la primera remite al nivel "óntico", el segundo término refiere a lo "ontológico". Lo óntico (policy) tiene que ver con las "cosas" de la política, es decir, con la multiplicidad de prácticas e instituciones de la política convencional (con sus leyes, reglamentos, protocolos); mientras que lo ontológico (politics) tiene que ver con un modo posible de subjetivación, con el cómo se instituye la sociedad, con la distribución del poder, con el reconocimiento y los afectos, con la reproducción ideológica, con la dimensión del antagonismo propio del acontecer social 10,23,24.

En este contexto vertiginoso que estamos atravesando hay, como vimos, una interpelación convocante de los sujetos -individuales y colectivos- a asumir un posicionamiento subjetivo (fiel, reactivo u oscuro) desde el cual afrontar el acontecimiento, por lo cual habrá una confrontación práctica y también discursiva entre los diferentes actores. Todo orden social implica de algún modo una articulación temporal y precaria de prácticas hegemónicas que pretenden establecer algún orden en un contexto de contingencia, y más aún en circunstancias tan complejas como las que nos ocupan. En tal sentido, el desafío de la política y de lo político, es conseguir que dicha confrontación sea de carácter "agonista”, a fin de garantizar mayores niveles de participación democrática durante el enfrentamiento de la adversidad 24,25. Lo que en términos de nuestro querido maestro Mario Testa, implica hacer un uso positivo de las contradicciones y los conflictos suscitados durante dicho enfrentamiento adversarial 26,27.

Así, esta confrontación se da en y por el "sentido común”, entendido como el resultado de una articulación discursiva de "lo múltiple” pasible de ser modificada por intervenciones contrahegemónicas, es decir, por un conjunto de fuerzas en permanente tensión, en permanente disputa, tendientes a la consolidación de una voluntad colectiva sostenida por afectos comunes, que idealmente aspiren a un orden más inclusivo e igualitario; capaz de debilitar a su vez, los afectos comunes -todavía culturalmente dominantes- que sostienen la hegemonía neoliberal 15,25.

Lo que se pretende, desde esta línea de pensamiento, es superar la visión descriptiva y prescriptiva de "la política" a partir del análisis y la actuación en "lo político", tensionando las relaciones de poder -y de los afectos- que mantienen las desigualdades entre las clases, influyendo decididamente en el rol jugado por el Estado ante la irrupción acontecimiental 28,29,30. Pero esto, hay que asumirlo, constituye una expresión de deseos con muchísimas dificultades prácticas para su concreción en el contexto de incertidumbre actual, marcado por las implacables consecuencias de la pandemia. ¿Por qué? Porque la situación extraordinaria demanda que, como fue dicho y en pos de conseguir una necesaria eficacia pragmática, el Estado fije su posición formalmente con políticas de carácter normativo-prescriptivo, lo que conlleva el riesgo -también advertido por Badiou 11 - de que todo sitio de acontecimiento acabe sufriendo una normalización estatal alienante, con sus consecuencias en lo político, lo económico, lo cultural y lo social.

Este planteamiento que impresiona, muy enfocado en lo macro, propongo llevarlo, como reflexión, al territorio del trabajo en salud, porque creo que la implementación de "la política", tal como el propio acontecimiento la demanda, implica una lógica (un modo de elaborar el razonamiento) donde -en situación- lo urgente desplaza a lo importante 31,32. Donde la perspectiva de las disciplinas “verticales", con la cual se formaron todos los gobernantes y gestores, aborda el problema de un modo que no se 
condice con su verdadera complejidad, dado que estamos ante un problema que atraviesa transversalmente -sin respetar- dichas perspectivas 33. Donde y por lo antedicho, se promueve un abordaje que tiende a descontextualizar su objeto de estudio e intervención 34 , y se lo "ontologiza”, dando lugar a que "la pandemia" o "la COVID-19" devengan un ser-ente "con vida propia" que invisibiliza a quienes la padecen, esa compleja multiplicidad de sujetos en contextos tan diferentes 35 . Por ende, la estrategia, es decir, el modo en que se implementa "la política" 32, tiende a reforzar -de no mediar una profunda reflexión y reorientación de las prácticas- las características del modelo médico hegemónico, biologicista y centrado en la enfermedad, individualista, mercantilista, a-cultural, a-histórico, y basado en una eficacia pragmática intervencionista y medicamentosa 36,37; consolidando aún más, un modelo de atención hospitalocéntrico, alejado de los cuidados del primer nivel, enfocado en las demandas más que en las necesidades, desde la exclusiva perspectiva del riesgo y con poca consideración de las vulnerabilidades singulares, así como de la determinación social más profunda de tales procesos 38 . De hecho, y en lo que atañe a este último aspecto, ya nadie habla de las causas originarias de este acontecimiento; causas que, como sabemos, no son de origen "divino", sino puramente humano, y, vale decirlo, vinculadas con el sistema de producción.

La propia lógica de implementación de "la política”, implica entonces prácticas centradas en los procedimientos orientados por las "tecnologías duras" (los respiradores, la vacuna) y "duras-blandas" (los conocimientos expertos de carácter disciplinar: la infectología, la epidemiología, la medicina intensivista...), con poca reflexión y acción (no hay espacio ni tiempo para la discusión y comprensión) sobre los padecimientos. Reflexión y acción, mediadas fundamentalmente por "tecnologías blandas" (relacionales, intersubjetivas, vinculares), no solo con los enfermos y sus familiares, sino también entre los trabajadores y con la propia comunidad: "lo [micro] político" 39,40,41,42. En suma, una supremacía de las tecnologías duras orientando las prácticas, en detrimento de las leves (blandas), en una situación donde éstas últimas debieran adquirir una importancia crucial, dada la complejidad y severidad vinculadas con la grave interpelación de la vida (propia, ajena, y colectiva) que atravesamos. Un ejemplo empírico de esto lo constituye el hecho de que, durante los primeros cuatro meses de pandemia, "el tendón de Aquiles" de "la política" lo encarnaba, para los medios de comunicación, la posible insuficiencia del sistema para garantizar las tecnologías "duras" necesarias (camas hospitalarias, extrahospitalarias, respiradores), mientras que recién ahora, durante el pico de las consecuencias, pareciera tomarse alguna conciencia de que son los "recursos humanos" y su vulneración objetiva y subjetiva (sobrecarga laboral y tensión afectiva) la principal limitación.

Entonces, lo que está en juego, es la posibilidad de procesar y abordar este acontecimiento y sus consecuencias de un modo lo más saludable posible, entre todos y para todos. Pero es difícil conseguirlo, en un contexto donde es reforzada permanentemente una cultura de la desconfianza, de intolerancia con la diferencia, del miedo, donde todos somos potencialmente "contagiosos" y por consiguiente cuasi enemigos; donde se anula la empatía con el otro. Si alguien enferma, pasa a ser un estigmatizado más 43. Además, y como vimos, la propia lógica de implementación de "la política" basada en las tecnologías más duras, favorece una verticalización de las organizaciones sanitarias en la cual lo instituido restringe las prácticas de carácter instituyente 44 . Así, estas "burocracias profesionales", que en circunstancias habituales cuentan con amplios márgenes de autonomía en su base operativa, facilitando el trabajo interdisciplinario, creativo, devienen, en esta coyuntura, "burocracias mecánicas”, piramidales, profundizándose la fragmentación y la desvinculación que conducen a la alienación de sus trabajadores 45,46. Esta encerrona alienante es en la que nos encontramos los trabajadores de la salud, porque en el transcurso de pocos meses hemos sido "héroes" (aplaudidos desde los balcones de los edificios) y "villanos" (que no podían ingresar al edificio de su domicilio por la hostilidad de sus propios vecinos); lo que ha generado incluso en algunos grupos profesionales un reflujo corporativo que tampoco ayuda, ni a ellos, ni al "nosotros" más amplio que integran, ni a nadie. En síntesis, un empinado tobogán reaccionario que nos precipita hacia la fragmentación y la oscuridad.

Lo "concreto", en este contexto, queda reducido a cuántos nuevos infectados hubo en las últimas 24 horas, cuántos nuevos fallecidos, cuál es la tasa de replicación viral, cuántos respiradores nos quedan disponibles...; cuando se sabe desde Marx y su Introducción General a la Crítica de la Economía Política de 185747 (p. 51), que "lo concreto es concreto, porque es la síntesis de múltiples determinaciones". Sin embargo, esta compleja trama de múltiples determinaciones queda invisibilizada, se desconsidera que lo concreto es "la unidad de lo múltiple" 47 (p. 28), y, por lo tanto, aquellos datos constituyen más 
bien una abstracción que nos devuelve a la máscara, al semblante que oculta lo real, y entonces se hace necesario retomar nuevamente el desafío de mantener abierta "la caverna", y salir de ella en lo posible fortaleciendo vínculos. Y recuperar viejas categorías -no por esto menos útiles- como, por ejemplo, lo "concreto pensado" de Karel Kosík 48, para evitar la "naturalización” de lo social; sabiendo, también gracias a Marx, que para esto "no basta que el pensamiento procure acercarse a su realización, también la realidad debe tratar de acercarse al pensamiento" 49 (p. 101).

Hay posibilidades de hacer cosas transformadoras a partir de todo lo develado (desenmascarado) por el acontecimiento, a pesar de las urgencias, a pesar de sus tremendas consecuencias, a pesar de la empinada pendiente del tobogán reaccionario en que nos encontramos. Y estos quehaceres y comohaceres nuestros, fieles, reflexionados, y colectivos por convicción, también repercutirán favorablemente en lo ideológico comunal 32,50. De lo contrario, el modo intervencionista en que opera "la política" continuará reforzando un habitus tecnocrático de los trabajadores socio-sanitarios 51 . Una preponderante configuración subjetiva de agentes técnico-normativos reactivos, más que intérpretes-mediadores capaces de constituirse en actores sociales fieles al acontecimiento 52; con su repercusión obvia en el reforzamiento de una conciencia colectiva mayormente biológica, poco ecológica, y nada social 32.

Todo amplificado a su vez por la violencia simbólica de los medios masivos de comunicación, y su apelación permanente a la metáfora "bélica", enfocada ciegamente en un enemigo identificable a erradicar para "que todo vuelva a estar bien", reforzando el posicionamiento subjetivo oscuro, hostil, al que hemos aludido; o incluso incrementando en otros -trabajadores fieles al acontecimiento, pero sensibles a esta retórica-, una actitud sacrificial que tampoco es recomendable 53. Es muy difícil para los trabajadores del campo socio-sanitario posicionarse en este contexto vertiginoso de un modo creativo, solidario y cuidador, que trascienda el posicionamiento instrumental conservador; cuando los medios de comunicación masiva replican continuamente un imaginario sanitario tan hegemónico y machista, porque los discursos más progresistas, feministas, que conciben a la salud como un derecho, no los ha permeado 54. Esta "infodemia" generadora de temor, ansiedad, desconcierto, parálisis, en su pendular mortífero entre lo sanitario y lo económico, entorpece toda posibilidad de lograr un cuidado solidario y colectivo responsable que trascienda la mera preservación individual, o a lo sumo un control poblacional focalizado y vertical, con la discriminación, estigmatización y exclusión que esto conlleva 53,55.

¿Cómo lograr una articulación agonista entre un Estado responsable (representación), trabajadores comprometidos, y la comunidad organizada (presentación), cuando estamos atravesados por estos múltiples embates? ¿Cómo avanzar evitando dos extremos metafóricos tan habituales como poco prometedores: por un lado la idea del "paraíso" al que nos conducirá "la vacuna”, y por el otro, el "apocalipsis" donde todo el planeta perecerá irremediablemente 42 ? En cuanto a la primera de estas metáforas digamos que, la tan ansiada "normalidad" anterior (el semblante, la máscara, la caverna) dejaba muchísimo que desear, además de ser la que nos condujo a esta situación; y respecto del pronóstico pesimista, digamos que no será este virus el que arrase con el planeta, sino más bien el sistema de producción del cual el virus es un pobre producto más.

Esta situación implica un desafío múltiple mayor para los trabajadores del campo socio-sanitario (así como para la sociedad en su conjunto), en tanto nos demanda el desarrollo de aptitudes y actitudes críticas superadoras 26 , un pensamiento estratégico activo 32 , así como la consolidación de una conducta militante capaz de conciliar lo científico con lo socio-histórico y lo político 34 . Es decir, atributos micropolíticos, relacionales, intersubjetivos, vinculares, muy importantes, pero que son precisamente los más vulnerados en este contexto de aislamiento y separación. Deberemos reforzarlos sin descuidarnos. Solo así evitaremos recaer en cuestiones que ya hemos discutido profundamente con la intención de dejarlas atrás, pero que paradójicamente están siendo potenciadas a partir de esta situación, como por ejemplo: que "la política" se anteponga a "lo político"; que la epidemiología quede reducida a la infectología -con algo de estadística-; que vuelva a apelarse a la planificación normativa que Matus y Testa criticaron de un modo definitivo -por su contundencia- hace ya muchos años; que la gerencia y la mera administración de recursos remplacen a la gestión y al gobierno; que el positivismo científico y el estructural-funcionalismo desplacen al constructivismo y al pensamiento crítico; en suma, que lo macropolítico subsuma a lo micropolítico 56.

Hemos escuchado muchas veces en estos meses, la siguiente frase: "el virus no discrimina". En una sociedad tan desigual e injusta como la nuestra, el virus sí lo hace, dado que refuerza y profundiza 
todas y cada una de las diferencias injustas prexistentes. Tomando ahora cierta distancia del posicionamiento de Badiou, digamos que, ojalá comprendamos que el Estado presente, junto a la comunidad organizada, en actitud fiel ante el acontecimiento, son la principal alternativa con la que contamos para garantizar los mayores niveles de salud y bienestar posibles para el pueblo. Su concreción es difícil e implica una compleja alquimia entre coincidir y co-incidir, que suele ser fuente también de conflictividad y mayores niveles de incertidumbre. Que dicha conflictividad adquiera un carácter agonístico, superando al antagonismo infructuoso, es nuestro principal desafío como sociedad 24. En definitiva, la palabra "pandemia", desde su propia etimología 57, remite a la idea de "reunión de todo un pueblo".

\section{Consideraciones finales}

Si bien un acontecimiento como el analizado excede por definición su marco estructural, también puede hacerlo el surgimiento de una novedosa subjetividad colectiva que se posicione firmemente ante la interpelación acontecimiental, a pesar de sus condicionamientos coyunturales y emergentes. La combinación de "la política" estatal responsable con "lo político" de los actores sociales comprometidos e integrados constituye una posibilidad concreta de hacerle frente a sus graves consecuencias. Por esto la lucha es en gran medida de carácter situacional, cultural, discursiva, ideológica, relacional, intersubjetiva, es decir, micropolítica; más que económica y macropolítica 42 . Por lo mismo, nos compromete a todos. Solo así podrá emprenderse una verdadera ruptura con la pulsión de repetición del statu quo, simbolizado en este trabajo con la metáfora de la caverna y su semblante simulucrativo conservador 1,2. Evitemos que la pandemia devenga una nueva caverna simbólica que nos impida pensar y actuar responsablemente por garantizar la salud como derecho inalienable del pueblo.

Los resultados definitivos de la pandemia y su abordaje en nuestro país, como sucede con todo acontecimiento, se calificarán por sus efectos -y por la comparación con los de otros países-, en forma retrospectiva; momento que impresiona estar lejos aún.

Por lo cual, finalicemos diciendo que en el trabajo en salud y en la política, como en el amor, la verdad 58, la fidelidad a un suceso acontecimiental, se produce en el "encuentro"; que siempre implica el riesgo de confrontación con lo real, el afuera de la caverna simbólica. Y es precisamente esto lo que ha dificultado la pandemia, la posibilidad de generar un acontecimiento a partir de la apuesta decidida al encuentro intersubjetivo (lo cual no implica, obviamente, no cumplir con el aislamiento social, preventivo y obligatorio). Por lo tanto, saquémosle de una vez el carácter de "acontecimiento" a la pandemia; ya es solo un hecho. Grave, sí, pero un hecho, y el acontecimiento no es el hecho, sino las consecuencias que seremos capaces de producir a partir de sus consecuencias. Las activaciones intersubjetivas iniciadas, pensadas y desarrolladas en un procedimiento fiel a partir de su interpelación 14; lo que podamos construir y movilizar como colectivo organizado ante su irrupción. Por lo tanto, “...seamos fieles al acontecimiento que somos” 11 (p. 263). Desear este acontecimiento de afirmación transfiguradora de la realidad y de nosotros mismos, por la vida, es el antídoto para la patología del régimen colonial, capitalista y patriarcal que nos hace desear el goce del poder miserable, conservador, oscuro, narcisista y devastador 42 . Aprovechemos esta coyuntura, en la medida en que podamos, para constituirnos en sujetos militantes activos de una praxis orientada a la construcción de "lo común", porque es una deuda grande que tenemos con los otros y con nosotros mismos.

El amor, en el trabajo en salud y en la política, es la búsqueda de la igualdad experimentada colectivamente. Las palabras y los cuerpos, resonando responsablemente juntos -aun virtualmente-, son los portadores de la Idea. 


\section{Información adicional}

ORCID: Leonardo Federico (0000-0002-37968416).

\section{Referencias}

1. Badiou A. La República de Platón: diálogo en un prólogo, dieciséis capítulos y un epílogo. Buenos Aires: Fondo de Cultura Económica; 2013.

2. Badiou A. En busca de lo real perdido. Buenos Aires: Amorrortu; 2016.

3. Therborn G. La ideología del poder y el poder como ideología. Madrid: Siglo XXI Editores; 1987.

4. Therborn G. ¿Cómo domina la clase dominante? 5a Ed. Madrid: Siglo XXI Editores; 1997.

5. Badiou A. ¿Se puede pensar la política? Buenos Aires: Ediciones Nueva Visión; 1990.

6. Badiou A. La filosofía frente al comunismo: de Sartre a hoy. Buenos Aires: Siglo Veintiuno Editores; 2016.

7. Badiou A. Qué entiendo yo por marxismo. Buenos Aires: Siglo Veintiuno Editores; 2019.

8. Santos BS. La cruel pedagogía del virus. Buenos Aires: Consejo Latinoamericano de Ciencias Sociales; 2020.

9. Žižek S. ¡Pandemia!: COVID-19 sacude al mundo. Nueva York: OR Books; 2020.

10. Badiou A. Compendio de metapolítica. Buenos Aires: Prometeo Libros; 2009.

11. Badiou A. El ser y el acontecimiento. Buenos Aires: Manantial; 2015.

12. Badiou A. Movimiento social y representación política. Antroposmoderno 2018; 4 may. http://antroposmoderno.com/antro-articulo. php?id_articulo $=631$.

13. Badiou A. Segundo manifiesto por la filosofía. Buenos Aires: Manantial; 2010.

14. Badiou A. Condiciones. Buenos Aires: Siglo Veintiuno Editores; 2015.

15. Alemán J. Horizontes neoliberales en la subjetividad. Olivos: Grama Ediciones; 2016.

16. Santos BS. Una epistemología del sur: la reinvención del conocimiento y la emancipación social. Ciudad de México: Siglo XXI/Consejo Latinoamericano de Ciencias Sociales; 2009.

17. Therborn G. Los campos de exterminio de la desigualdad. Buenos Aires: Fondo de Cultura Económica; 2015.

18. Santos BS. La caída del Angelus Novus: ensayos para una nueva teoría social y una nueva práctica política. Bogotá: Instituto Latinoamericano de Servicios Legales Alternativos/Universidad Nacional de Colombia; 2003.
19. Badiou A, Gouchet M. ¿Qué hacer? Diálogo sobre el comunismo, el capitalismo y el futuro de la democracia. Buenos Aires: Edhasa; 2015.

20. Badiou A. Elogio del amor. Buenos Aires: Paidós; 2012.

21. Badiou A, Milner JC. Controversia: diálogo sobre la política y la filosofía de nuestro tiempo. Buenos Aires: Edhasa; 2014.

22. Badiou A. Metafísica de la felicidad real. Buenos Aires: Adriana Hidalgo Editora; 2017.

23. Mouffe Ch. En torno a lo político. Buenos Aires: Fondo de Cultura Económica; 2011.

24. Mouffe Ch. Agonística: pensar el mundo políticamente. Buenos Aires: Fondo de Cultura Económica; 2014.

25. Mouffe Ch. Por un populismo de izquierda. Buenos Aires: Siglo XXI Editores Argentina; 2018.

26. Testa M. Decidir en salud: ¿Quién?, ¿Cómo? y ¿Por qué? Salud Colect 2007; 3:247-57.

27. Federico L. Análise política em saúde: a contribuição do pensamento estratégico. Salvador: EDUFBA; 2015.

28. Viana ALA, Baptista TWF. Análise de políticas de saúde. In: Giovanella L, Escorel S, Lobato LVC, Noronha JC, Carvalho AI, organizadores. Políticas e sistema de saúde no Brasil. Rio de Janeiro: Editora Fiocruz; 2008. p. 65-105.

29. Lordon F. Capitalismo, deseo y servidumbre: Marx y Spinoza. Buenos Aires: Tinta Limón; 2015.

30. Lordon F. La sociedad de los afectos: por un estructuralismo de las pasiones. Buenos Aires: Adriana Hidalgo Editora; 2018.

31. Matus C. Adiós, señor presidente. Remedios de Escalada: Ediciones de la UNLa; 2007.

32. Testa M. Pensamiento estratégico y lógica de programación (el caso de salud). Buenos Aires: Lugar Editorial; 1995.

33. Matus C. Escuela de Gobierno. Salud Colect 2007; 3:203-12.

34. Testa M. Saber en salud. Buenos Aires: Lugar Editorial; 1997.

35. Campos GWS. Gestión en salud: en defensa de la vida. Buenos Aires: Lugar Editorial; 2001.

36. Menéndez E. El modelo médico y la salud de los trabajadores. Salud Colect 2005; 1:9-32. 
37. Menéndez E. De saberes médicos tradicionales, populares y científicos: relaciones y dinámicas racistas en la vida cotidiana. Buenos $\mathrm{Ai}$ res: Lugar Editorial; 2018.

38. Paim JS. Modelos de atenção à saúde no Brasil. In: Giovanella L, Escorel S, Lobato LVC, Noronha JC, Carvalho AI, organizadores. Políticas e sistema de saúde no Brasil. Rio de Janeiro: Editora Fiocruz; 2008. p. 547-73.

39. Guattari F, Rolnik S. Micropolítica: cartografía del deseo. Buenos Aires: Tinta Limón/Traficantes de Sueños; 2005.

40. Merhy EE. Salud: cartografía del trabajo vivo. Buenos Aires: Lugar Editorial; 2006.

41. Franco TB, Merhy EE. Trabajo, producción del cuidado y subjetividad en salud: textos seleccionados. Buenos Aires: Lugar Editorial; 2016.

42. Rolnik S. Esferas de la insurrección. Apuntes para descolonizar el inconsciente. Buenos Aires: Tinta Limón; 2019.

43. Goffman E. Estigma: la identidad deteriorada. 2a Ed. Buenos Aires: Amorrortu; 2019.

44. Lourau R. El análisis institucional. Buenos Aires: Amorrortu; 2007.

45. Mintzberg H. Diseño de organizaciones eficientes. Buenos Aires: El Ateneo; 1983.

46. Castoriadis C. La institución imaginaria de la sociedad. Buenos Aires: Tusquets Editores; 2010.

47. Marx K. Introducción general a la crítica de la economía política. 21a Ed. Ciudad de México: Siglo XXI Editores; 1989.

48. Kosík K. Dialéctica de lo concreto: estudio sobre los problemas del hombre y el mundo. Ciudad de México: Grijalbo; 1967.
49. Marx K. Contribución a la crítica de la filosofía del derecho de Hegel. In: Tarcus H, editor. Antología. Buenos Aires: Siglo Veintiuno Editores; 2015. p. 91-106.

50. Testa M. Pensar en salud. Buenos Aires: Lugar Editorial; 1993

51. Bourdieu P, Wacquant L. Una invitación a la sociología reflexiva. Buenos Aires: Siglo XXI Editores; 2009.

52. Granda E. ¿A quéllamamos salud colectiva, hoy? Rev Cubana Salud Pública 2004; 30(2). http:// scielo.sld.cu/scielo.php?script $=$ sci_arttext \&pid=S0864-34662004000200009\&lng=es.

53. Stolkiner A. El campo de la salud mental y sus prácticas en la situación de pandemia. Revista Soberanía Sanitaria 2020; 4:22-6.

54. Tajer D. Sanitarismo feminista y políticas de cuidado. Revista Soberanía Sanitaria 2020; 4:58-63.

55. Kohen J. El trabajo y la salud en tiempos de pandemia. Revista Soberanía Sanitaria 2020; 4:71-8.

56. Spinelli H, Arakaki J, Federico L. Gobernantes y gestores: las capacidades de Gobierno a través de narrativas, puntos de vista y representaciones. Remedios de Escalada: Ediciones de la UNLa; 2019.

57. Real Academia Española. Pandemia. In: Diccionario de la lengua española. http://dle.rae. es/?id=Ta2HMYR.

58. Badiou A. Lógicas de los mundos. El ser y el acontecimiento 2. Buenos Aires: Ediciones Manantial; 2008. 
Abstract

The COVID-19 pandemic has taken the world by surprise, disturbing the previous situation affecting countries and the situation of their respective States. "Reality" has been redefined by the pandemic's serious effects. Argentina is no exception, and the citizenry and the State itself have thus been challenged to take a unique position based on values and to conduct action to deal with the consequences in both the immediate and medium terms. Therefore, the current Essay views the pandemic in terms of an "event", according to the concept proposed by French philosopher Alain Badiou, and analyzes its implications for individual and collective subjectivation, the values orienting practices, the role of the communications media, and the position taken by the Argentine State; as well as the more specific repercussions on health policy and healthcare work, drawing on other theoretical references from the field. The essay highlights the way "policy" is implemented in the current context: if it fails to mediate in-depth reflection and reorientation of practices, prioritizing the micropolitical sphere, it will result in greater disaggregation and alienation of individual and collective subjects. Thus, the event, more than the pandemic, which is already a fact, should be constituted by the intersubjective articulation of a healthy approach to its consequences, tending towards comprehensiveness and equality in defense of life.

Pandemics: Health Policy; Work

\section{Resumo}

A pandemia de COVID-19 irrompeu no mundo de forma surpreendente, perturbando o estado anterior da situação dos países afetados, bem como a situação de seus respectivos Estados. "O real" foi ressignificado de suas derivações graves. A Argentina não é exceção e, portanto, seus cidadãos e o próprio Estado foram questionados e convocados a assumir uma posição única baseada em valores $e$ a realizar ações destinadas a enfrentar suas consequências, imediatas e mediatas. Por isso, neste Ensaio a pandemia é pensada em termos de "acontecimento", seguindo a proposta conceitual do filósofo francês Alain Badiou, e suas implicações na subjetivação individual e coletiva, os valores que norteiam as práticas, o papel da mídia e a posição assumida pelo Estado argentino; bem como suas repercussões mais específicas na politica de saúde e no trabalho, recorrendo a outros referenciais teóricos da área. Ressalta-se que a forma como a "política" se concretiza no contexto atual, se não houver profunda reflexão e reorientação das práticas priorizando a micropolítica, resultará em um maior desengajamento e alienação dos sujeitos individuais e coletivos. O evento então, mais do que a pandemia, que já é um fato, deve se constituir na articulação intersubjetiva de uma abordagem saudável de suas consequências, visando a integralidade e a igualdade em defesa da vida.

Pandemias; Política de Saúde; Trabalho

Recibido el 11/Ago/2020

Aprobado el 08/Ene/2021 